\title{
Proposed Protocol for Neuropathic Pain Assessment
}

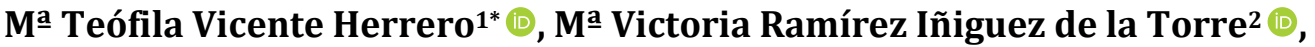 \\ Luis Reinoso Barbero ${ }^{3}$ [D
}

${ }^{1}$ Asociacion Española de Especialistas en Medicina del Trabajo, Madrid, Spain Occupational Health and Safety Services of Correos, Valencia, Spain

${ }^{2}$ Asociacion Española de Especialistas en Medicina del Trabajo, Madrid, Spain Occupational Health and Safety Services of Correos, Albacete, Spain

${ }^{3}$ Asociacion Española de Especialistas en Medicina del Trabajo, Madrid, Spain Occupational Medicine Service Grupo Banco Santander, Madrid, Spain Faculty of Health Sciences, Universidad Internacional de la Rioja, La Rioja, Spain

Email: *vicenteherreromt@gmail.com

How to cite this paper: Vicente Herrero, M.T., Ramírez Iñiguez de la Torre, M.V., Reinoso Barbero, L. (2020) Proposed Protocol for Neuropathic Pain Assessment. Occupational Diseases and Environmental Medicine, 8, 149-162.

https://doi.org/10.4236/odem.2020.84012

Received: September 1, 2020

Accepted: September 27, 2020

Published: September 30, 2020

Copyright (c) 2020 by author(s) and Scientific Research Publishing Inc.

This work is licensed under the Creative Commons Attribution International License (CC BY 4.0).

http://creativecommons.org/licenses/by/4.0/

\begin{abstract}
Introduction: Pain with neuropathic characteristics is one of the most limiting as a consequence of injury or disease that affects the somatosensory system. Objective: An assessment protocol is proposed to quantify the impact of neuropathic pain integrating personal, clinical, work and social aspects and to establish guidelines in its management and evolutionary control. Method: The medical literature on neuropathic pain and its impact is reviewed as a basis for including the variables that must be part of the protocol. Results: The variables are quantified individually and by groups of factors. The final result is stratified into four grades (mild, moderate, severe, extreme), which will serve for the subsequent control, monitoring and prevention of risks. Conclusion: The proposed protocol evaluates the impact of neuropathic pain in all aspects of the person who suffers it and quantifies the results establishing degrees for its control, follow-up and clinical, social and occupational intervention.
\end{abstract}

\section{Keywords}

Neuropathic Pain, Limitations, Assessment, Occupational Health, Occupational Medicine

\section{Introduction}

The concept of pain has been changing over the years. One of the most widely accepted pain definitions today is the one proposed by the International Associ- 
ation for the Study of Pain (IASP), which defines it as an unpleasant sensory and emotional experience with actual or potential tissue damage, or described in terms of such damage [1].

Neuropathic pain $(\mathrm{NeP})$ is understood as the result of an injury or disease that affects the somatosensory system [2] and can be classified according to its location (central or peripheral), its distribution (localized or diffuse), its etiology or production mechanisms.

The most characteristic symptom of DN is the painful or burning sensation (dysesthesia), together with hyperalgesia (exaggerated response to pain) or and allodynia (perception of any stimulus as painful), characteristic of an altered hypersensitivity, making the difference between positive sensory symptoms and negative [3].

The special group on the study of neuropathic pain (NeuPSIG) proposed a classification system to guide decisions about the level of certainty with which $\mathrm{NeP}$ can be determined in a patient: possible, probable, and definitive [4].

In reference to the guidelines for the therapeutic management of $\mathrm{NeP}$, consensus recommendations are followed and complementary treatment algorithms have been developed for use in the Primary Care setting and by non-pain specialists [5] [6], as well as those recommended by Special Interest IASP Group on Neuropathic Pain (NeuPSIG) for peripheral and localized neuropathic pain [7].

The objective of this work is to propose a protocol for the assessment of $\mathrm{NeP}$ that allows quantifying its impact in the personal, health, work and social environment and to establish guidelines for its management, evolution and adaptation in the work environment.

\section{Method}

Prior to including the variables in the protocol, a review of the existing scientific literature on the global concept of $\mathrm{NeP}$ and its relationship with work, social impact and quality of life was carried out. The search was done in Medline through the PubMed platform (https://pubmed.ncbi.nlm.nih.gov/), free access and with wide international coverage. The search period was limited to the 10 years prior to the start of the study (2009-2019) and, especially, to the last 5 years, including classified journal articles (editorials, originals, letters, reviews, clinical notes). The search strategy has been based on relating neuropathic pain with specific aspects of the occupational world. The MeSH headings used were: "neuropathic pain" "neuropathic pain and work" "neuropathic pain and work neurotoxicity" "neuropathic pain and work health".

Based on the results found in this review, elements to evaluate the impact and repercussion of DN were included in the protocol: personal aspects, with a global assessment of 10 points (age, level of training or education, economic situation, support from the environment-understanding as such the support of family members, cohabiting friends at home or of aid agencies or entities- and employment situation); clinical and care aspects, with a global assessment of 50 
points (pain, muscle tone, function or muscle balance based on the modified Medical Research Council Scale [8], peripheral pulses-associated, vascular alterations, neurological involvement-sensory, motor, reflex alteration, sphincter alteration, gait disorders, complementary examinations-electromyography); therapeutic aspects (effectiveness of the treatment, side effects and comorbidities); labor aspects, with a global score of 30 points, med a self-created preventive labor check-list; and social aspects-quality of life, with a global score of 10 points, for which the use of the HAQ questionnaire is proposed.

Each of these aspects is scored individually to obtain a maximum total score of 100 points. The limitation is stratified in scores according to the final punctuation: 0 - 25 points, mild score; 26 - 50 points, moderate score; 51 - 75 points, severe score and 76 - 100 points, extreme score.

\section{Protocol}

Based on current evidence and taking into account the changes that scientific research is permanently incorporating, different evaluation parameters have been included in this Neuropathic Pain Assessment Protocol, structured in four sections, to reach a final assessment. The aspects to be assessed are summarized in Figure 1 and detailed in Tables 1-4.

This is a proposal that has not been validated at the present time.

Table 1. Personal aspects related to neuropathic pain impact.

\begin{tabular}{|c|c|c|}
\hline & & Points \\
\hline \multirow{3}{*}{ Age } & $<30$ years & 0 \\
\hline & $31-65$ years & 1 \\
\hline & $>65$ years & 2 \\
\hline \multirow{3}{*}{ Educational level } & Primary/elementary education & 2 \\
\hline & Secondary education & 1 \\
\hline & Higher education & 0 \\
\hline \multirow{3}{*}{ Economic situation } & Bad (insufficient income) & 2 \\
\hline & $\begin{array}{l}\text { Medium (it is not possible to face } \\
\text { extraordinary expenses) }\end{array}$ & 1 \\
\hline & $\begin{array}{l}\text { Good (it is possible to face extraordinary } \\
\text { expenses) }\end{array}$ & 0 \\
\hline \multirow{3}{*}{$\begin{array}{l}\text { Support system (personal-family, friend, } \\
\text { caregiver- or in entities-day center, } \\
\text { physiotherapy ... -depending on need) }\end{array}$} & No support (no support) & 2 \\
\hline & $\begin{array}{l}\text { Partial support (less than } 50 \% \text { of the time } \\
\text { needed) }\end{array}$ & 1 \\
\hline & Full/good support ( $100 \%$ of the time needed) & 0 \\
\hline \multirow{4}{*}{$\begin{array}{l}\text { Employment situation: Unemployment, } \\
\text { not in the labor force. In case of being } \\
\text { employed: Temporary Disability in the } \\
\text { last year }\end{array}$} & Unemployment - not in the labor force & 1 \\
\hline & No sick leave or $\mathrm{TD}<3$ months/year & 0 \\
\hline & $\mathrm{TD}>6$ months/year & 1 \\
\hline & TD $>6$ months/year & 2 \\
\hline
\end{tabular}


M. T. Vicente Herrero et al.

Table 2. Clinical and therapeutic aspects related to neuropathic pain impact.

Pain

Points

Intensity (max. 5 points)_VAS scale

Minimum (0 - 1)

Mild (2 - 4)

Moderate (5 - 7)

Severe $(8-10)$

Frequency (max 5 points)

Intermittent (once a month)

Sporadic (a few times every week)

Frequent (several days a week)

Constant (daily)

Duration (max. 5 points)

Hours

Days

Weeks

Months/years

distribution ( $\max 5$ points)

Located

radiating

Referred

Diffuse

Associated signs (max. 5 points)

Alterations in limb alignment or limb dysmetria

Muscular atrophy

Joint deformity

Maintained antalgic posture

Neurovegetative involvement: vasomotor alterations (hyperthermia, vasodilation, acrocyanosis), sweating or trophic disorders of the skin and appendages.

Muscle Tone (max. 2 points)

Hypertonia

Normal

Hypotonia

Absent

Muscle strength ( $\max 5$ points) Modified scale of the MRC (Medical Research Council)

Absent: total paralysis. (Active muscle contraction is not detected)

Minimal: visible muscle contraction without movement.

(Some muscle contraction can be seen or palpated, without movement) 


\section{Continued}

Regular: partial movement only against gravity

(Slight contraction possible against gravity)

Regular+: full motion only against gravity

Good-: full motion against gravity and minimal resistance

(Movement possible against gravity and little resistance)

Good+: full movement against gravity and strong resistance

Normal: full movement against full resistance.

(Normal contraction force compared to the opposite side)

Vascular assessment -pulses- ( $\max =2$ points)

Increased

Normal

Diminished

Absent

Neurological repercussion (max. 7 points)

Paresthesias/dysesthesias

Sensory disorders

Hyperalgesia

Allodynia

Anesthesia

None

Motor disorders

Paresis

Paralysis

Abolished

Diminished

Reflexes

Normal

Hyperactive without clonus

Hyperactive with clonus

Complementary tests: Electromyography (max. 3 points)

Normal

Neurapraxia

Neurogenesis

Axonotnesis

Therapeutic aspects (max. 4 Points) * If the patient is not receiving treatment, the assessment will not be applied until it starts and has been with it for at least 3 months. 


\section{Continued}

\begin{tabular}{|c|c|c|c|c|}
\hline $\begin{array}{l}\text { Adverse effects of treatment } \\
\text { (Max. } 2 \text { points) }\end{array}$ & $\begin{array}{l}\text { Dige: } \\
\text { altera } \\
\text { Neur } \\
\text { cons } \\
\text { Imm } \\
\text { Card } \\
\text { rhyth } \\
\text { Resp } \\
\text { bron } \\
\text { Kidn } \\
\text { Othe }\end{array}$ & $\begin{array}{l}\text { s, ulcer, intestinal } \\
\text { wsiness, altered } \\
\text { cts } \\
\text { ypertension, hypotension, } \\
\text { mbosis. } \\
\text { tion of the upper tract, } \\
\text { dema, pleurisy ... } \\
\text { ilure, lithiasis, nephritis ... } \\
\text { visual disturbances }\end{array}$ & $\begin{array}{l}\text { Mild } \leq 1 \text { effects } \\
\text { Moderate }=2 \text { o } 3 \text { effects }\end{array}$ & 0.5 \\
\hline \multicolumn{5}{|c|}{$\begin{array}{l}\text { Associated pathologies (max } 2 \text { points) } * \text { Only those pathologies that modify the course or prognosis of the neuropathic pain } \\
\text { under evaluation are evaluated. }\end{array}$} \\
\hline Traumatological & Yes & No & \multirow{2}{*}{ Mild = 1 associated pathology } & \multirow{2}{*}{0} \\
\hline Cardiological & Yes & No & & \\
\hline $\begin{array}{l}\text { Dermatological: important skin lesions (large } \\
\text { scars for example) }\end{array}$ & Yes & No & \multirow{2}{*}{$\begin{array}{l}\text { Moderate }=2 \text { associated } \\
\text { pathologies }\end{array}$} & \multirow[t]{2}{*}{1} \\
\hline Vascular: arteriovenous or lymphatic lesions & Yes & No & & \\
\hline $\begin{array}{l}\text { Digestive: pathologies that interfere with the } \\
\text { treatment }\end{array}$ & Yes & No & \multirow{2}{*}{$\begin{array}{l}\text { Severe }=3 \text { or } 4 \text { associated } \\
\text { pathologies }\end{array}$} & \multirow{2}{*}{1.5} \\
\hline $\begin{array}{l}\text { Psychiatric: conditions that coexist or interfere } \\
\text { with the treatment }\end{array}$ & Yes & No & & \\
\hline Autonomic nervous system disorders & Yes & No & $\begin{array}{l}\text { Very severe: } 5 \text { or more } \\
\text { associated pathologies }\end{array}$ & 2 \\
\hline
\end{tabular}

Table 3. Labor aspects related to neuropathic pain impact: CHECK LIST.

\begin{tabular}{|c|c|c|c|c|c|}
\hline \multicolumn{2}{|r|}{ Labor Tasks-Score (between 0 - 6) } & $\begin{array}{c}\text { Not } \\
\text { applicable }\end{array}$ & $\begin{array}{l}1 / 3 \\
\text { day }\end{array}$ & $\begin{array}{l}2 / 3 \\
\text { day }\end{array}$ & \\
\hline & $\mathrm{MML} \leq 5 \mathrm{~kg}$ & 0 & 1 & 2 & 3 \\
\hline \multirow{3}{*}{$\begin{array}{l}\text { Manual } \\
\text { mobilization of } \\
\text { loads }\end{array}$} & MML 5 - $10 \mathrm{~kg}$ & 0 & 2 & 3 & 4 \\
\hline & MML $10-25 \mathrm{~kg}$ & 0 & 3 & 4 & 5 \\
\hline & MML $>25 \mathrm{~kg}$ & 0 & 4 & 5 & 6 \\
\hline \multicolumn{6}{|c|}{ Manual mobilization of loads Score: ___ (max. 9 points) } \\
\hline & MR Shoulder elevation $>90^{\circ}$ & 0 & 2 & 4 & 6 \\
\hline \multirow[t]{2}{*}{$\begin{array}{l}\text { Repetitive } \\
\text { movements }\end{array}$} & $\begin{array}{l}\text { MR flexion and extension or prono-supination } \\
\text { of the wrist }\end{array}$ & 0 & 2 & 4 & 6 \\
\hline & Flexion and extension. Trunk or lower limbs & 0 & 2 & 4 & 6 \\
\hline \multicolumn{6}{|c|}{ Repetitive movements Score:___ (max. 18 points) } \\
\hline & Prolonged ambulation & 0 & 2 & 4 & 6 \\
\hline \multirow{2}{*}{ Prolonged postures } & Standing or continued sitting & 0 & 2 & 4 & 6 \\
\hline & $\begin{array}{l}\text { Other fixed positions and without alternation } \\
\text { of positions in your work }\end{array}$ & 0 & 2 & 4 & 6 \\
\hline \multicolumn{6}{|c|}{ Prolonged postures Score:___ (max. 6 points) } \\
\hline Work organization & $\begin{array}{l}\text { Continuous work, with repetitive/monotonous } \\
\text { tasks and without the alternating of tasks }\end{array}$ & 0 & 2 & 4 & 6 \\
\hline
\end{tabular}




\section{Continued}

There is no adequate relationship with

bosses/colleagues

The workload is inadequate (excessive, irregular, not adapted to their abilities ...)

Impossibility of taking rest breaks during work

It is impossible for the worker to complete the tasks assigned to them

The job consists of shift work (assess the monthly shift)

Work organization Score: (max. 36 points)

The environmental conditions of the patient's job (temperature, humidity ...) worsen their clinical picture

There are no support elements for the tasks (devices, instruments, machines ...)

The worker is exposed to noise $>85 \mathrm{dBA}$ or peaks of noise $>140 \mathrm{dBA}$

Worked is performed at height $(>3 \mathrm{~m})$

Working condition

Work is carried out in confined spaces (tunnel, drain, pit ...)

The worker carries out live electrical work

Regular/prolonged driving is performed

Machines or tools with vibration are handled

Neurotoxic chemicals are handled

The worker is to biological contaminants

The worker performs tasks that require high attention/concentration

$\begin{array}{llll}0 & 2 & 4 & 6 \\ 0 & 2 & 4 & 6 \\ 0 & 2 & 4 & 6 \\ 0 & 2 & 4 & 6 \\ 0 & 2 & 4 & 6\end{array}$




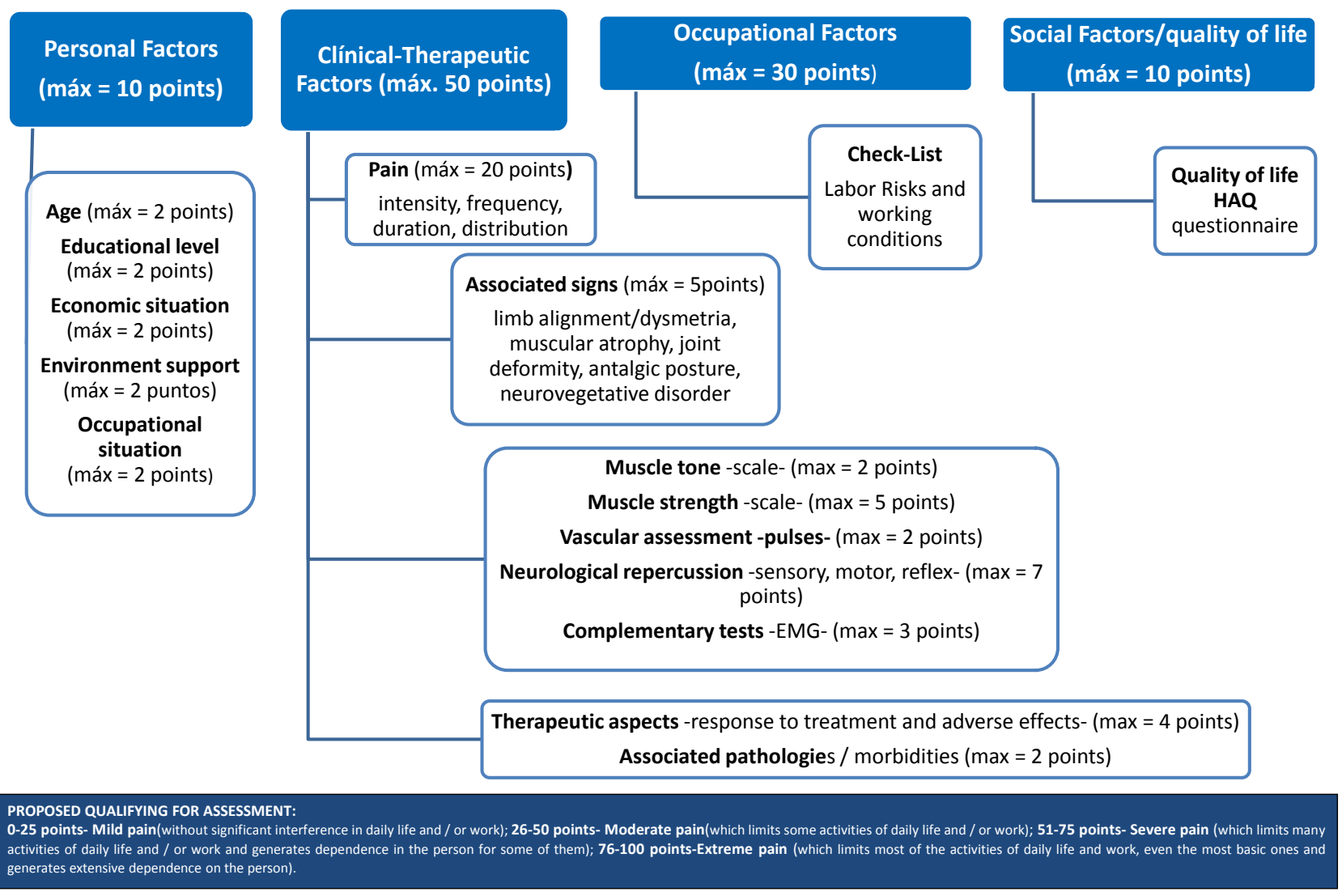

Figure 1. Protocol for assessment of neuropathic pain in occupational health.

\section{Discussion}

The medical bibliography collected in databases specialized in health sciences (PUBMED) shows studies on NeP that estimate its prevalence at around 7\% $10 \%$ of the general population, with an increasing trend, probably associated with the increase in diseases that accompany the aging of the world population, changes in lifestyle, the increase in the incidence of diabetes mellitus, and the improvement of treatments for some diseases, such as cancer survival after chemotherapy, but with subsequent adverse effects. This means that the burden of chronic NeP is also increasing and has repercussions on economic, health and quality of life costs for the affected people. Therefore, personalized interventions are recommended with a multidisciplinary approach to the management of this disease [9].

The causes of NeP can be multiple. The Tax Society Pain Taxonomy (AAPT) developed, in collaboration with different public and private entities, diagnostic criteria for central $\mathrm{NeP}$ that are organized according to the multidimensional framework of the AAPT: central diagnostic criteria, common characteristics, medical comorbidities and common psychiatric, neurobiological, psychosocial and functional consequences and supposed neurobiological and psychosocial mechanisms, risk factors and protective factors [10].

But if its diagnosis is complex and its etiology and epidemiology varied, the 
therapeutic management is more complicated, which requires periodic updates. NeuPSIG affirms that the inadequate response to pharmacological treatments constitutes a substantial unmet need in patients with $\mathrm{NeP}$ and recommends for future trials the use of pain relief scales, patient and physician global impression of change, validated measures of patient quality. $\mathrm{NeP}$ and sleep assessment, assessment of mood, functional capacity, and quality of life [11].

From an occupational point of view, the medical bibliography contains specific publications on prevalent pathologies, caused or aggravated by work, with associated NeP. Among others, the carpal tunnel syndrome [12] [13] [14] and chronic cervical and lumbar pain [15]; The relationship of age, gender and tobacco consumption with this group of pathologies that present with chronic $\mathrm{NeP}$ is also relevant [16] [17] [18]. Post-traumatic pain directly affects the work environment, especially after traumatic occupational accidents and commuting or traffic accidents during work, and its management is often complex since appropriate treatment options must be considered to minimize the sequelae [19].

Highlight as specific $\mathrm{NeP}$ in the workplace that is derived from exposures to neurotoxic substances, such as acute carbon monoxide poisoning or late neurotoxicity due to toluene, where early action is essential to prevent the development of neuropathy and improve prognosis [20].

The scientific literature collects data that support the fact that the presence of $\mathrm{NeP}$ is associated with a greater burden of disease in the population, with chronicity in its evolution and that is reflected in terms of quality of life, health status, work experience and direct medical costs [21]. Along with the personal, individual cost, the cost of $\mathrm{NeP}$ for society must be assessed for all aspects: direct medical costs, loss of ability to work, loss of caregivers' ability to work and possibly increased need for institutionalization or other assistance for daily life activities. A more complete estimate of efficacy, utility and costs would facilitate future research regarding the profitability of the therapies used in the treatment of $\mathrm{NeP}$ [22].

In Spain, the experience of pain represents a substantial burden both for people and for the country's economy. It is reflected in the questionnaires commonly used to measure the impact of pain (both SF-12 and SF-6D) [23], especially with regard to severe pain, but it also implies less participation in work activity and greater absenteeism and presenteeism, with substantially higher patterns of use of health resources [24] [25]. The researchers affirm that this type of pain and its impact far outweighs the consequences provided by the more traditional assessments of health-related quality of life (HRQoL) deficits, in addition to being the main factor associated with increased visits medical, emergency services and in need of hospitalizations [26].

The basis of this protocol is to homogenize the assessment of the impact of $\mathrm{NeP}$ including all those factors that may condition the result. Although many studies have evaluated individual aspects, such as the profitability of the treatments, the significant heterogeneity among them prevents reaching a homoge- 
neous synthesis of the results. The standardized methodology and the improved reports would allow more reliable comparisons between the studies [27]. Strategies are proposed to maximize the results, employing, when possible, agents that address both pain and comorbidities in order to restore function and improve function, quality of life of the patient [28].

Previously proposed assessment tools, such as the pain DETECT Project, already have long-standing experience, with more than 300,000 patients assessed, providing one of the world's largest data sets on chronic pain, and generating subgroups of patients based on their individual sensory profiles, with the idea of being able to stratify the treatment and, ultimately, to be able to reach a personalized therapy. Today, it is used for clinical and research purposes all around the world [29].

The protocol that we present here within the AlVaDoNe [30] project serves as a new tool, with a broad focus, although more specific in occupational health and that could be validated in the future.

\section{Preventive Recommendations}

The main preventive recommendation in relation to the protection of workers with chronic $\mathrm{NeP}$ is to reduce risk exposure and facilitate their social and occupational integration, through different actions:

- With correct health surveillance, care coordination in the process of diagnosis, treatment, control and monitoring by all those involved: occupational health, primary care and specialties, specifically with the pain units, hospital care and Organisms public health.

- With application, within the scope of the specific competencies of the Prevention Services, of all technical and sanitary measures aimed at reducing the risk in the work performance of the affected people to act, both in primary and secondary prevention, or limit their consequences through all available options: training and specific information for workers; adoption of organizational and preventive measures, collective and individual; health surveillance aimed at detection and protection of especially sensitive workers; and coordinated care work.

It is recommended:

1) In cases of mild pain, without significant interference in daily life and/or work, preventive surveillance actions.

2) In cases of moderate pain, which limits some activities of daily life and/or work, in addition to preventive surveillance, assess possible adaptations that minimize the risk in their usual work or job changes.

3) In cases of severe pain, which limits many activities of daily life and/or work and generates some type of dependence on the person for some of them, assess actions for processing temporary and/or permanent disability and, in any case, support the affected person with the necessary reports for its processing.

4) In cases of extreme pain, which limits the majority of activities of daily life 
and work, even the most basic and generates extensive dependence on the person, facilitate management towards disability and disability procedures and support the affected person with the necessary reports for its processing.

\section{Conclusions}

In Spain, Law 31/1995, on Occupational Risk Prevention (LPRL) [31] establishes the right of workers to effective protection in terms of safety and health at work. One of the instruments used by Occupational Medicine to control and monitor the working health population status and the impact of working conditions on them is Health Surveillance, through an individualized assessment of each worker with the performance of specific medical examinations based on the risks of the position (individual surveillance), and a subsequent joint analysis of all the results obtained in the company (collective surveillance).

The assessment of work aptitude is the evaluation of the psychophysical capacity of the individual to carry out their work without risk to their own health or that of others, based on the relationship between work demands and the health of the individual who is going to do it.

It is the final result of the specific evaluation of the health state as an individual health intervention within the framework of the surveillance of the worker's health, and it is also necessary for the Occupational Physician to have a thorough knowledge of the detailed demands and requirements of the job, understanding by job the set formed by the physical place, the tools, tasks, duties and responsibilities assigned to a person in a work environment.

For the assessment from the perspective of Health Surveillance of a worker with $\mathrm{NeP}$, the clinical history and physical examination are particularly relevant, since in most cases the results of the complementary tests have little correlation with the functional impairment of these patients. The clinical history should collect the severity and evolution of the symptoms and the functional repercussion they entail, analyze the response to the received treatments and their repercussion in the physical and emotional spheres. In a complementary way, the necessary laboratory or imaging examinations will be added, the most useful being electromyography.

The NeP Assessment Protocol is shown as a tool that helps the professional to assess the consequences of $\mathrm{NeP}$ in the patient's daily life, socially and at work.

No patient/worker should be evaluated without having diagnostic confirmation of neuropathic pain: clinical data and, if possible, confirmation of nerve injury with electromyography.

In all cases, for a global assessment in the workplace of the patient with $\mathrm{NeP}$, in addition to the clinical-therapeutic aspects, it is necessary to consider personal and work aspects, due to their interrelation with pain and the influence of pain on the quality of social and work life of the patient/worker.

\section{Conflicts of Interest}

There is no conflict of interest. This work has had the support of Grunnenthal 
for the computerization of the protocol (AlVaDoNe) and with the scientific endorsement of the Spanish Association of Specialists in Occupational Medicine (AEEMT).

\section{References}

[1] International Association for the Study of Pain. IASP Terminology. Pain Terms. https://www.iasp-pain.org/Education/Content.aspx?ItemNumber=169

[2] Treede, R.D., Jensen, T.S., Campbell, J.N., Cruccu, G., Dostrovsky, J.O., Griffin, J.W., et al. (2008) Neuropathic Pain: Redefinition and a Grading System for Clinical and Research Purposes. Neurology, 70, 1630-1635.

https://doi.org/10.1212/01.wnl.0000282763.29778.59

[3] Correa, I.G. (2014) Dolor neuropático. Clasificación y estrategias de manejo para médicos generals. Revista Médica Clínica Las Condes, 25, 189-199. https://doi.org/10.1016/S0716-8640(14)70030-6

[4] Finnerup, N., Haroutounian, S., Kamerman, P., Baron, R., Bennett, D., Bouhassira, D., et al. (2016) Neuropathic Pain: An Updated Grading System for Research and Clinical Practice. Pain, 157, 1599-606. https://doi.org/10.1097/j.pain.0000000000000492

[5] Alcántara Montero, A. and Ibor Vidal, P.J. (2018) Un algoritmo de tratamiento farmacológico para el dolor neuropático localizado. Semergen, 44, 71-75. https://doi.org/10.1016/j.semerg.2016.10.004

[6] Finnerup, N.B., Attal, N., Haroutounian, S., McNicol, E., Baron, R., Dworkin, R.H., et al. (2015) Pharmacotherapy for Neuropathic Pain in Adults: A Systematic Review and Meta-Analysis. The Lancet Neurology, 14, 162-173. https://doi.org/10.1016/S1474-4422(14)70251-0

[7] International Association for the Study of Pain. Neuropathic Pain (NeuPSIG) Publications \& Guidelines. https://www.iasp-pain.org/Education/Content.aspx?ItemNumber=6530

[8] Medical Research Council of de UK, 1976. https://mrc.ukri.org/research/facilities-and-resources-for-researchers/mrc-scales/m rc-muscle-scale/

[9] Colloca, L., Ludman, T., Bouhassira, D., Baron, R., Dickenson, A.H., Yarnitsky, D., et al. (2017) Neuropathic Pain. Nature Reviews Disease Primers, 3, Article No. 17002. https://doi.org/10.1038/nrdp.2017.2

[10] Widerström-Noga, E., Loeser, J.D., Jensen, T.S. and Finnerup, N.B. (2017) AAPT Diagnostic Criteria for Central Neuropathic Pain. The Journal of Pain, 18, 1417-1426. https://doi.org/10.1016/j.jpain.2017.06.003

[11] Haanpää, M., Attal, N., Backonja, M., Baron, R., Bennett, M., Bouhassira, D., et al. (2011) NeuPSIG Guidelines on neuropathic Pain Assessment. Pain, 152, 14-27. https://doi.org/10.1016/j.pain.2010.07.031

[12] Lazaro, R.P. and Eagan, T.S. (2017) Concurrent Musculoskeletal and Soft Tissue Pain in the Upper Extremity Can Affect the Treatment and Prognosis of Carpal Tunnel Syndrome: Redefining a Common Condition. Journal of Pain Research, 10, 2497-2502. https://doi.org/10.2147/JPR.S142153

[13] Fan, Z.J., Harris-Adamson, C., Gerr, F., Eisen, E.A., Hegmann, K.T., Bao, S., et al. (2015) Associations between Workplace Factors and Carpal Tunnel Syndrome: A Multi-Site Cross Sectional Study. American Journal of Industrial Medicine, 58, 509-518. https://doi.org/10.1002/ajim.22443 
[14] Harris-Adamson, C., Eisen, E.A., Neophytou, A., Kapellusch, J., Garg, A., Hegmann, K.T., et al. (2016) Biomechanical and Psychosocial Exposures Are Independent Risk Factors for Carpal Tunnel Syndrome: Assessment of Confounding Using Causal Diagrams. Occupational and Environmental Medicine, 73, 727-734. https://doi.org/10.1136/oemed-2016-103634

[15] Sihawong, R., Sitthipornvorakul, E., Paksaichol, A. and Janwantanakul, P. (2016) Predictors for Chronic Neck and Low Back Pain in Office Workers: A 1-Year Prospective Cohort Study. Journal of Occupational Health, 58, 16-24.

https://doi.org/10.1539/joh.15-0168-OA

[16] Marin, T.J., Van Eerd, D., Irvin, E., Couban, R., Koes, B.W., Malmivaara, A., et al. (2017) Multidisciplinary Biopsychosocial Rehabilitation for Subacute Low Back Pain. Cochrane Database of Systematic Reviews, 6, CD002193. https://doi.org/10.1002/14651858.CD002193.pub2

[17] Salt, E., Wright, C., Kelly, S. and Dean, A. (2011) A Systematic Literature Review on the Effectiveness of Non-Invasive Therapy for Cervicobrachial Pain. Manual Therapy, 16, 53-65. https://doi.org/10.1016/j.math.2010.09.005

[18] Kostova, V. and Koleva, M. (2001) Back Disorders (Low Back Pain, Cervicobrachial and Lumbosacral Radicular Syndromes) and Some Related Risk Factors. Journal of the Neurological Sciences, 192, 17-25. https://doi.org/10.1016/S0022-510X(01)00585-8

[19] Hatch, M.N., Cushing, T.R., Carlson, G.D. and Chang, E.Y. (2018) Neuropathic Pain and SCI: Identification and Treatment Strategies in the 21st Century. Journal of the Neurological Sciences, 384, 75-83. https://doi.org/10.1016/j.jns.2017.11.018

[20] Park, G.Y., Kwon, D.R. and Jung, W.B. (2018) Unilateral Brachial Plexus Injury Following Carbon Monoxide Intoxication: A Case Report. Medicine, 97, e11699. https://doi.org/10.1097/MD.0000000000011699

[21] Langley, P.C., Van Litsenburg, C., Cappelleri, J.C. and Carroll, D. (2013) The Burden Associated with Neuropathic Pain in Western Europe. Journal of Medical Economics, 16, 85-95. https://doi.org/10.3111/13696998.2012.729548

[22] O’Connor, A.B. (2009) Neuropathic Pain: Quality-Of-Life Impact, Costs and Cost Effectiveness of Therapy. PharmacoEconomics, 27, 95-112. https://doi.org/10.2165/00019053-200927020-00002

[23] Vilagut, G., Ferrer, M., Rajmil, L., Rebollo, P., Permanyer-Miralda, G., Quintana, J.M., et al. (2005) El Cuestionario de Salud SF-36 español: Una década de experiencia y nuevos desarrollos. Gaceta Sanitaria, 19, 135-150.

http://scielo.isciii.es/scielo.php?script=sci_arttext\&pid=S0213-91112005000200007

\&lng=es

https://doi.org/10.1157/13074369

[24] Langley, P.C., Ruiz-Iban, M.A., Molina, J.T., De Andres, J. and Castellón, J.R.G.-E. (2011) The Prevalence, Correlates and Treatment of Pain in Spain. Journal of Medical Economics, 14, 367-380. https://doi.org/10.3111/13696998.2011.583303

[25] Langley, P.C., Molina, J.T., Ferri, C.M., Hernández, C.P., Varillas, A.T. and Ruiz-Iban, M.A. (2011) The Association of Pain with Labor Force Participation, Absenteeism, and Presenteeism in Spain. Journal of Medical Economics, 14, 835-845.

https://doi.org/10.3111/13696998.2011.632045

[26] Langley, P., Hernández, C.P., Ferri, C.M., Hidalgo, D.R. and López, M.L. (2011) Pain, Health Related Quality of Life and Healthcare Resource Utilization in Spain. Journal of Medical Economics, 14, 628-638. https://doi.org/10.3111/13696998.2011.604369 
[27] Ruiz-Negrón, N., Menon, J., King, J.B., Ma, J.J. and Bellows, B.K. (2019) Cost-Effectiveness of Treatment Options for Neuropathic Pain: A Systematic Review. PharmacoEconomics, 37, 669-688.

https://doi.org/10.1007/s40273-018-00761-6

[28] Nicholson, B. and Verma, S. (2004) Comorbidities in Chronic Neuropathic Pain. Pain Medicine, 5, S9-S27. https://doi.org/10.1111/j.1526-4637.2004.04019.x

[29] Freynhagen, R., Tölle, T.R., Gockel, U. and Baron, R. (2016) The painDETECT Project-Far More than a Screening Tool on Neuropathic Pain. Current Medical Research and Opinion, 32, 1033-1057. https://doi.org/10.1185/03007995.2016.1157460

[30] ALVADONE. Evaluación de un Algoritmo de Valoración del Dolor Neuropático. http://www.alvadone.es

[31] España. Ley 31/1995, de 8 de noviembre, de prevención de Riesgos Laborales. (B.O.E. de 10 de Noviembre de 1995). 